\title{
BMJ Open Is there a correlation between an eGFR slope measured over a 5-year period and incident cardiovascular events in the following 5 years among a Flemish general practice population: a retrospective cohort study
}

\author{
Gijs Van Pottelbergh, ${ }^{1}$ Pavlos Mamouris, ${ }^{1}$ Nele Opdeweegh, ${ }^{1}$ Bert Vaes, ${ }^{1}$ \\ Geert Goderis, ${ }^{1}$ Marjan Van Den Akker ${ }^{1,2}$
}

To cite: Van Pottelbergh G, Mamouris $\mathrm{P}$, Opdeweegh $\mathrm{N}$, et al. Is there a correlation between an eGFR slope measured over a 5 -year period and incident cardiovascular events in the following 5 years among a Flemish general practice population: a retrospective cohort study. BMJ Open 2018;8:e023594. doi:10.1136/ bmjopen-2018-023594

- Prepublication history for this paper is available online. To view these files, please visit the journal online (http://dx.doi org/10.1136/bmjopen-2018023594).

Received 24 April 2018 Revised 11 September 2018 Accepted 4 October 2018

Check for updates

(C) Author(s) (or their employer(s)) 2018. Re-use permitted under CC BY-NC. No commercial re-use. See rights and permissions. Published by BMJ.

${ }^{1}$ Department of Public Health and Primary Care, KU Leuven, Leuven, Belgium

${ }^{2}$ School for Public Health and Primary Care, Faculty of Health, Medicine and Life Sciences, Maastricht University, Maastricht, The Netherlands

Correspondence to Dr Gijs Van Pottelbergh; gijs.vanpottelbergh@kuleuven. be

\section{ABSTRACT}

Objectives To examine if the estimated glomerular filtration rate (eGFR) slope over a 5-year period is related to incident cardiovascular (CV) events in the following 5 years.

Design Retrospective cohort study.

Setting Primary care.

Participants All patients aged $\geq 50$ years with at least four eGFR measurements between 01 January 2006 and 31 December 2010 were included in the study.

Outcome measures During the follow-up period ( 01 January 2011 until 31 December 2015), CV events (acute myocardial infarction, stroke (cerebrovascular accident (CVA)/ transient ischemic attack (TIA)), peripheral arterial disease and acute heart failure) were identified.

Methods The slope was calculated by the least square method (in $\mathrm{mL} / \mathrm{min} /$ year). The following slope categories were considered: $(-1$ to 1$),(-3$ to -1$)(-5$ to -3$), \leq-5$, (1 to 3 ), (3 to 5 ) and $\geq 5.00 \mathrm{~mL} / \mathrm{min} /$ year. Cox proportional hazards model was used to assess the association between eGFR slope and incidence of CV events. Survival probability from CV events was estimated per slope category.

Results 19567 patients had at least four eGFR measurements, of whom $52 \%$ was female. $12 \%$ of the $\leq-5$ slope category developed a new CV event in comparison to $7.8 \%$ of the reference group and $5.4 \%$ of the $\geq 5$ slope category. Survival rates were worst in those with a slope $\leq-5$. Patients with a slope of $(-5$ to -3$)$ and $\leq-5$ had an adjusted HR of 1.37 and 1.55 , respectively. Most patients with a slope $<-3 \mathrm{~mL} / \mathrm{min}$ had an eGFR still $>60 \mathrm{~mL} / \mathrm{min}$. Conclusions Negative eGFR slopes of at least $3 \mathrm{~mL} / \mathrm{min} /$ year give irrespectively of the eGFR itself a higher risk of CV events compared with patient groups with stable or improved kidney function. So the eGFR slope identifies an easy to define group of patients with a high risk for developing CV events.

\section{INTRODUCTION}

Loss of kidney function due to advanced age is a normal phenomenon. Changes in glomerular filtration rate (GFR) are a consequence
Strengths and limitations of this study

- The study included a large population with four estimated glomerular filtration rate measurements in different time periods, representative of the general population.

- Data were collected over 10 years.

- Proteinuria, smoking status and body mass index were not included in the analyses.

- Using a real-life dataset means that there was an important loss to follow-up due to a combination of mortality and change of general practitioner.

of haemodynamic and structural changes, including loss of renal mass. ${ }^{1}$ In the Flemish part of Belgium, the prevalence of chronic kidney disease (CKD) is estimated at $13 \%$ in men and $16 \%$ in women. ${ }^{2}$

Only a few patients with CKD will progress to end-stage renal disease because most of them will die of other causes such as cardiovascular (CV) disease. Risk factors that contribute to the development of end-stage renal disease are diabetes, high cholesterol, high Low density lipoprotein (LDL), hypertension and female gender. ${ }^{34}$ However, an estimated GFR (eGFR) persistently ( $\geq 3$ months) dropping below $60 \mathrm{~mL} / \mathrm{min} / 1.73 \mathrm{~m}^{2}$ signifies CKD and is associated with a higher risk of complications. In patients with CKD, hospitalisation rates are higher and they have an increased risk of CV disease and death. ${ }^{56}$ Rapid decline of kidney function is suggested to cause a higher incidence of CV events such as acute myocardial infarction (AMI), heart failure, stroke (cerebrovascular accident (CVA) or TIA (transient ischemic attack (TIA)) and peripheral artery disease. ${ }^{78}$ The higher CV 
risk in CKD is often under-recognised and undertreated in primary care. ${ }^{9}$

The eGFR slope represents a more dynamic parameter compared with measurements taken at one point. ${ }^{10-13} \mathrm{~A}$ distinction can be made between stable eGFR $( \pm 1 \mathrm{~mL} /$ $\mathrm{min} /$ year $)$ and variable eGFR $( \pm 3$ or $\pm 5 \mathrm{~mL} / \mathrm{min} /$ year $)$. In their study on CV health, Shlipak et $a l^{8}$ found that especially a rapid decline of eGFR, defined as $>3 \mathrm{~mL} /$ min/year, indicates a higher risk of AMI, heart failure and stroke. Another study ${ }^{14}$ reports a similar correlation between eGFR decline and CV events. These studies add further evidence that changes in eGFR slope can give a worse CV outcome. This could be a relevant parameter for automatically generated CV risk calculations. However, before implementing the eGFR slope in risk calculations, it is essential to analyse its predictive value in population-based data and to analyse the subpopulation that has a strong decline in eGFR over time.

The objective of this study was to determine if the eGFR slope over a 5-year period is related to incident CV events defined as AMI, peripheral arterial disease (PAD), CVA/ TIA and acute heart failure (AHF) in the following 5 years in a Flemish general practice population.

\section{METHODS}

\section{Setting}

The present study is a retrospective data analysis using the INTEGO databank, which incorporates epidemiological data from more than 100 general practitioners (GPs) residing in the Flemish part of Belgium. In Medidoc, a medical software program, GPs use a coded registration system based on validated algorithms. ${ }^{15}$ The group of patients that visits the general practice at least once in 1 year is called the 'Yearly Contact Group'. From this database, all patients aged $\geq 50$ years between 1 January 2006 and 31 December 2010 were included in the study. The 5 -year period was divided in 10 subperiods of 6 months, that is, ' 1 January 2006 to 30 June 2006', '1 July 2006 to 31 December 2006' and so forth and only patients with measurements in at least four different time periods were included. The eGFR was calculated with the Modification in renal disease (MDRD) equation (GFR (mL/ $\left.\min / 1.73 \mathrm{~m}^{2}\right)=186 \times 16-1.154 \times($ age $)-0.203 \times(0.742$ if female $) \times(1.212$ if black $))$. With these measurements, we calculated the eGFR slope $(\mathrm{mL} / \mathrm{min} /$ year $)$ and divided the population into the following subgroups: $(-1.00,1.00)$ (reference group), $(-3.00,-1.00),(-5.00,-3.00), \leq-5.00$, $(1.00,3.00)(3.00,5.00)$ and $\geq 5.00 \mathrm{~mL} / \mathrm{min} / 1.73 \mathrm{~m}^{2}$ per year $(\mathrm{mL} / \mathrm{min} /$ year $)$. In case a patient had several measurements of creatinine values in the same semester, we included the mean value. We excluded patients of who did not visit their GP after 1 January 2011.

\section{Patient and public involvement}

Intego is a long-existing (22 years) database funded by the Flemish government. Patients or their representatives are not involved in the design of this database or research conducted on it.

\section{Outcome}

During the follow-up period, between 1 January 2011 and 31 December 2015, CV events described as incident (AMI, ICPC2-code K75 and/or K76), (AHF, K77), Stroke (TIA, CVA, K89; K90) and (PAD, K92) were identified. Patients with prior $\mathrm{CV}$ disease were not excluded. Patients who had had no contact with the GP in the follow-up period were censored. We considered the following variables as potential confounders: age, female gender, diabetes (T90), hypertension (K85, K86), baseline kidney function (last value in 5-year period) and history of CV event (codes K75, K76, K77, K89, K90, K92). Patients were censored on the data of their last contact during follow-up.

\section{Statistical analysis}

All analyses were performed using $\mathrm{R}$ software. We analysed the slope of eGFR by using the least-square method and baseline characteristics were measured on 01 January 2011. Next, Cox proportional hazards model was used to evaluate the association between eGFR slope and incidence of CV events. Since the proportional hazards model assumption held, we further calculated the HRs using three different models. Model 1 was the basic model and was adjusted for age and gender. Model 2 was adjusted for age, gender, hypertension, diabetes and CV event history. Lastly, model 3 in addition considered one more covariate, namely baseline kidney function, where we considered the last eGFR measurement before 1 January 2011.

\section{RESULTS}

The study population is described in table 1 . Inclusion criteria were met by 19567 patients and had different eGFR measurements in at least four different time periods. The mean age of this group was $66.1 \pm 11$.6years and 52\% (10 206) were women. We excluded 465 patients since we were not able to track the last time that they visited a GP. Patients with diabetes or hypertension were slightly more likely to be in the groups with a negative eGFR slope. A history of CV events was more common in the following groups: $\leq-5$ and $(-5$ to -3$)$. Table 1 also shows that $86.0 \%$ and $91.9 \%$ of the patients in the group with a slope $<-5$ and -5 to $-3 \mathrm{~mL} / \mathrm{min} /$ year, respectively had an eGFR $>60 \mathrm{~mL} / \mathrm{min}$.

Table 2 provides an overview of eGFR slope and CV event during follow-up. Nearly $12 \%$ of the patients in the category $\leq-5$ and ( -5 to -3$)$ had a new CV event compared with $7.8 \%$ of the reference group. In the (3 to 5) and $\geq 5$ group, a new event occurred only in about $6 \%$ of patients. Figure 1 displays the results of differences in survival time between patients belonging to any of previously defined slope groups. Also, an informative risk set table is added, which shows the number of patients who were under observation in the specific 


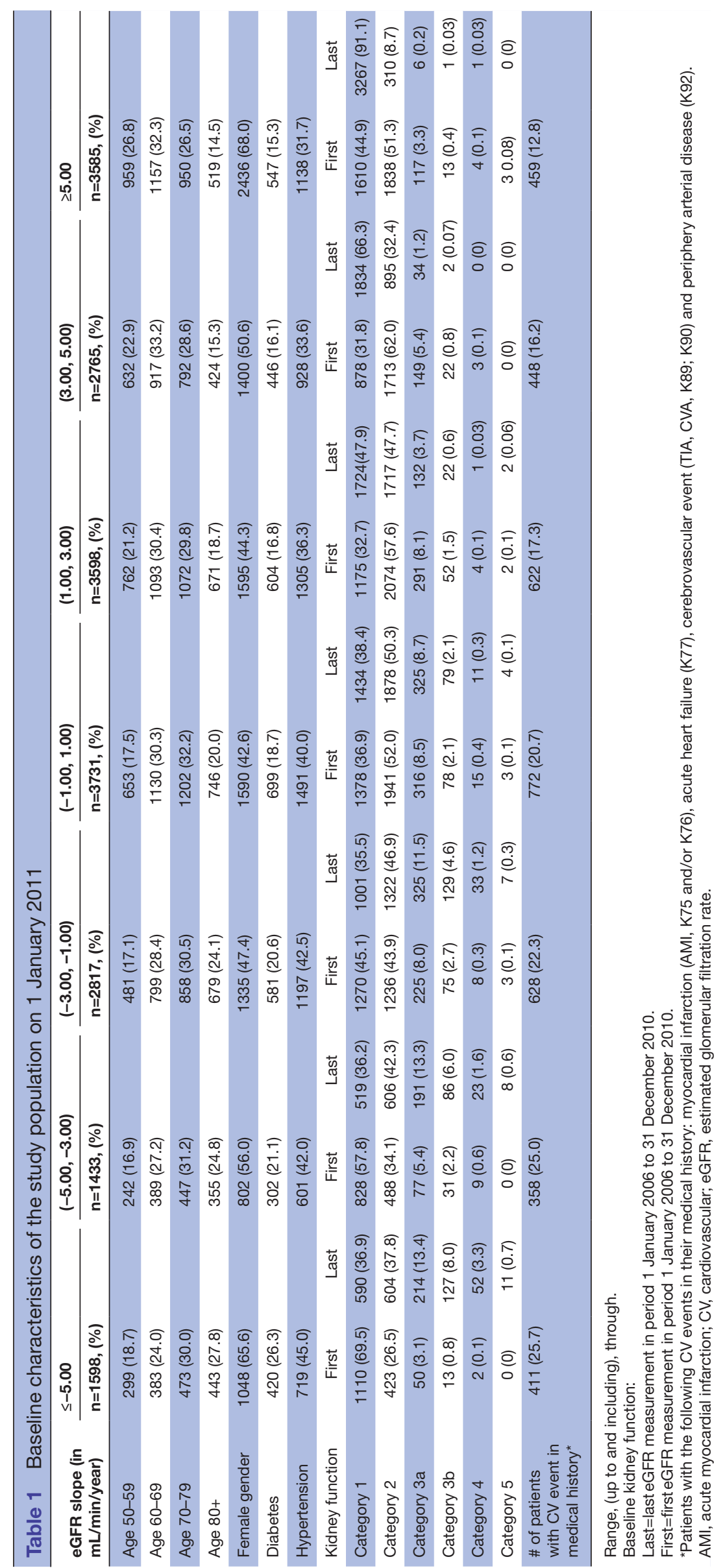


Table 2 Number of patients with a cardiovascular (CV) event and mean number of events, stratified to estimated glomerular filtration rate (eGFR) slope in follow-up period

\begin{tabular}{|c|c|c|c|c|c|c|c|}
\hline & $\leq-5.00$ & $(-5.00,-3.00)$ & $(-3.00,-1.00)$ & $(-1.00,1.00)$ & $(1.00,3.00)$ & $(3.00,5.00)$ & $\geq 5.00$ \\
\hline eGFR slope & $n=1598,(\%)$ & $n=1433,(\%)$ & $\mathrm{n}=2817,(\%)$ & $\mathrm{n}=3731,(\%)$ & $\mathrm{n}=3598,(\%)$ & $n=2765,(\%)$ & $\mathrm{n}=3585,(\%)$ \\
\hline $\begin{array}{l}\text { No of patients } \\
\text { with CV events }\end{array}$ & 192 (12.0) & 160 (11.2) & $272(9.7)$ & $292(7.8)$ & $249(6.9)$ & $175(6.3)$ & $193(5.4)$ \\
\hline $\begin{array}{l}\text { Absolute no of } \\
\mathrm{CV} \text { events }\end{array}$ & 225 & 173 & 302 & 319 & 278 & 187 & 216 \\
\hline
\end{tabular}

period. The risk table is indicative of how many people were available (or at risk) throughout this period. It appeared that those who had a slope $\geq 5$ had the best survival rate. Less than $10 \%$ suffered from CV event during the time of follow-up. The patients who had a slope ( -1 to 1,1 to 3 and 3 to 5$)$ had similar survival rates, but worse than those with a slope $\geq 5.00$. Next were the patients with slope $(-3$ to -1$)$, followed by $(-5$ to -3 ) and the worst survival rates were those with a slope $\leq-5$. Approximately $15 \%$ of the patients in slope category $\leq-5$ had a CV event in comparison to the reference group, where only $10 \%$ had an event.
An overview of the HRs and 95\% CI per adjusted model stratified to eGFR slope is given in table 3. The HRs of patients with a positive eGFR slope were all insignificant, whereas the HRs of the negative eGFR slopes were statistically significant. Patients who had a slope $\leq-5.00$ were 1.55 more likely to develop a CV event compared with those of $(-1.00,1.00)$. Similar interpretations hold for the other groups as well. The adjusted HR increased with a declining negative eGFR slope, for example, model 2; $1.19,1.37$ to 1.55 . Adjusting for comorbidity (hypertension, diabetes and CV event in history) attenuated the HR per category, while HR still remained significant for the

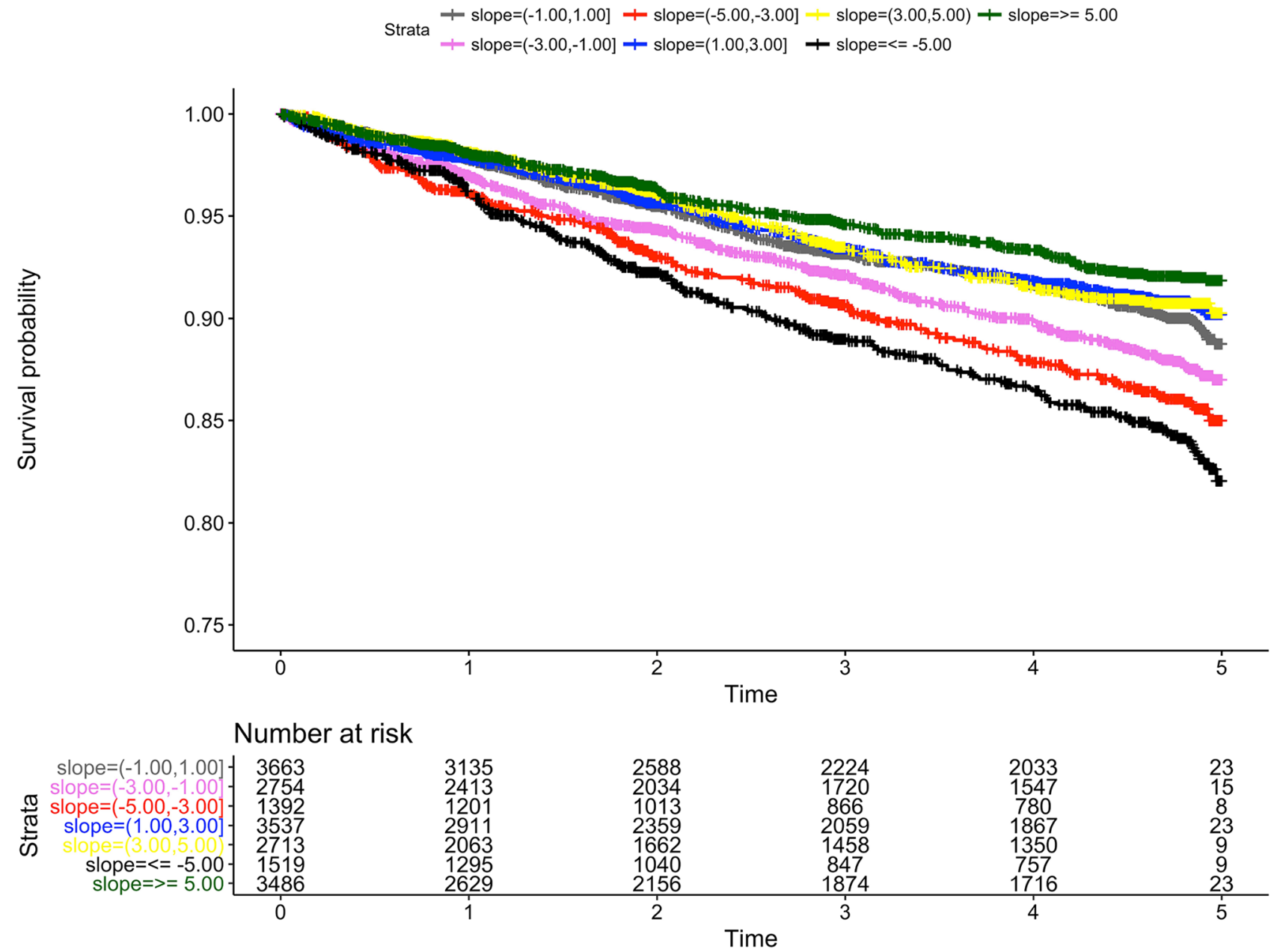

Figure 1 Estimates of survival probability in different years grouped by the 'slope categories' and risk set table with number of patients at risk per year. 
negative eGFR slopes. Adjusting for baseline kidney function of the last measurement (model 3) did not affect the HRs of model 2, indicating that this covariate was insignificant.

\section{DISCUSSION}

\section{eGFR slope and CV events: principal findings}

We used a large population to examine if a declining eGFR slope over a 5-year period can show subsequent worse CV outcome in the following 5 years. We found that patients with declining eGFR slope were more at risk of a CV event than those with stable or rising eGFR slope. The survival rates of patients with an eGFR slope $\leq-3.00 \mathrm{~mL} /$ $\mathrm{min} /$ year were worse than the survival rates in other groups. These data suggest that the eGFR slope can be prognostic for CV health irrespective of the eGFR itself. Using eGFR slope can identify a group of patients with a still normal or slightly decreased eGFR and still higher risk for $\mathrm{CV}$ events.

\section{Context of the results}

As to CV disease and eGFR slope, two recent studies with a large study population have been conducted. Naimark et $a l^{12}$ found in a large analysis of several existing cohort studies that eGFR changes, positive as well as negative, have a significant association with all-cause mortality, $\mathrm{CV}$ mortality and non-CV mortality. Turin et al investigated the association between eGFR change over 2.5 years and the risk of congestive heart failure (CHF), AMI and stroke. ${ }^{16}$ Risk of CHF, AMI and stroke was highest when eGFR decline was more than $-5 \mathrm{~mL} / \mathrm{min} /$ year. The adjusted HRs of CHF, AMI and stroke were 2.57, 1.31 and 1.29 , respectively. However, when adjusting for last eGFR measurement, a significant association was only seen with CHF (HR: 1.78).

When we adjusted for the last eGFR measurement, no significant difference in HR was seen, in contrast to the Turin study, which used a shorter time period and only three eGFR measurements. We did not find a U-shape relation between the eGFR slope and CV events as reported for the eGFR slope and mortality.

An important finding in this study is that an eGFR slope $<-3 \mathrm{~mL} / \mathrm{min} /$ year over a 5 -year time period based on at least four eGFR measurement predicts CV event independent of the eGFR itself. Moreover, most of our patients with a negative eGFR slope still have an eGFR above $60 \mathrm{~mL} / \mathrm{min}$. Hence, this eGFR slope identifies a risk group that cannot be identified using the eGFR only.

\section{Strengths and limitations}

The strength of this study is that we used a large population with four eGFR measurements in different time periods, representative of the general population. Another strong point is that we collected these data over 10 years using the first 5 years as predictor for the next 5 years. Other studies often used a shorter time period for gaining eGFR values or fewer eGFR values to calculate 
their slope, causing the result to be more sensitive to smaller eGFR variations.

Our study is limited in that we did not have sufficient information about proteinuria, smoking and body mass index to use it in the analyses without resulting in considerable bias. Finally, using a real-life dataset means that there is an important loss to follow-up due to the combination of mortality and change of GP.

\section{Recommendations}

We think it is useful to implement the eGFR slope into medical software programs and create an alert to warn the GP when a declining eGFR of at least $3 \mathrm{~mL} / \mathrm{min} /$ year is noticed and the patient is thus at risk of CV events. Implementing such an alert would contribute to the awareness of the GP more than personal intuition can do. The fact that most of the slope category $\leq-5.00$ had a normal kidney function at baseline is misleading and therefore deterioration of the eGFR slope can be underestimated if the eGFR slope is not taken into account.

To conclude, there is a correlation between eGFR slope over a 5-year time period and subsequent incident CV events. Negative eGFR slopes of at least $-3.00 \mathrm{~mL} /$ $\mathrm{min} /$ year predict a higher risk of CV events over a 5-year period than stable slopes or increasing slopes independently of the eGFR at baseline. Further research is needed to study if this deterioration responds to treatment and if so, which treatments or preventive measures should be taken. It remains to be investigated whether slowing down the process of declining kidney function also diminishes the incidence of $\mathrm{CV}$ events. For these reasons, an intervention study is needed that will assess these questions.

Contributors GVP, NO and MVDA performed the analyses and wrote the manuscript. PM extracted the data. GVP, MVDA, PM, BV and GG were responsible for the study concept, design and acquisition of participants and data. All authors participated in the interpretation of the data.

Funding Intego is funded on a regular basis by the Flemish Government (Ministry of Health and Welfare). This work would not have been possible without the collaboration of all general practitioners in the Intego network. We hereby state the independence of researchers from funders.

Competing interests None declared.

Patient consent Not required.

Ethics approval Intego procedures were approved by the ethical review board of the Medical School of the Catholic University of Leuven (No ML 1723) and by the Belgian Privacy Commission (no SCSZG/13/079).
Provenance and peer review Not commissioned; externally peer reviewed.

Data sharing statement All authors had full access to all of the data (including statistical reports and tables) in the study and can take responsibility for the integrity of the data and the accuracy of the data analysis.

Open access This is an open access article distributed in accordance with the Creative Commons Attribution Non Commercial (CC BY-NC 4.0) license, which permits others to distribute, remix, adapt, build upon this work non-commercially, and license their derivative works on different terms, provided the original work is properly cited, appropriate credit is given, any changes made indicated, and the use is non-commercial. See: http://creativecommons.org/licenses/by-nc/4.0/.

\section{REFERENCES}

1. Weinstein JR, Anderson S. The aging kidney: physiological changes. Adv Chronic Kidney Dis 2010;17:302-7.

2. Van Pottelbergh G, Bartholomeeusen S, Buntinx F, et al. The prevalence of chronic kidney disease in a Flemish primary care morbidity register. Age Ageing 2012;41:231-3.

3. Hostetter TH. Chronic kidney disease predicts cardiovascular disease. N Engl J Med 2004;351:1344-6.

4. Van Pottelbergh G, Bartholomeeusen S, Buntinx F, et al. The evolution of renal function and the incidence of end-stage renal disease in patients aged $\geq 50$ years. Nephrol Dial Transplant 2012;27:2297-303

5. Go AS, Chertow GM, Fan D, et al. Chronic kidney disease and the risks of death, cardiovascular events, and hospitalization. $N$ Engl J Med 2004;351:1296-305.

6. Manjunath $\mathrm{G}$, Tighiouart $\mathrm{H}$, Coresh $\mathrm{J}$, et al. Level of kidney function as a risk factor for cardiovascular outcomes in the elderly. Kidney Int 2003:63:1121-9.

7. Anavekar NS, McMurray JJ, Velazquez EJ, et al. Relation between renal dysfunction and cardiovascular outcomes after myocardial infarction. N Engl J Med 2004;351:1285-95.

8. Shlipak MG, Katz R, Kestenbaum B, et al. Rapid decline of kidney function increases cardiovascular risk in the elderly. J Am Soc Nephrol 2009;20:2625-30.

9. Razavian M, Heeley EL, Perkovic V, et al. Cardiovascular risk management in chronic kidney disease in general practice (the AusHEART study). Nephrology Dialysis Transplantation 2012;27:1396-402.

10. Vaes B, Beke E, Truyers C, et al. The correlation between blood pressure and kidney function decline in older people: a registrybased cohort study. BMJ Open 2015;5:e007571.

11. Van Pottelbergh G, Den Elzen WP, Degryse J, et al. Prediction of mortality and functional decline by changes in eGFR in the very elderly: the Leiden 85-plus study. BMC Geriatr 2013;13:61.

12. Naimark DM, Grams ME, Matsushita K, et al. Past decline versus current eGFR and subsequent mortality risk. J Am Soc Nephrol 2016;27:2456-66.

13. Turin TC, Coresh J, Tonelli M, et al. Change in the estimated glomerular filtration rate over time and risk of all-cause mortality. Kidney Int 2013;83:684-91.

14. Matsushita K, Selvin E, Bash LD, et al. Change in estimated GFR associates with coronary heart disease and mortality. J Am Soc Nephrol 2009;20:2617-24.

15. Truyers C, Steven E, Goderis G, et al. 20 jaar Huisartspraktijk in Vlaanderen: Acco, 2015.

16. Turin TC, Jun M, James MT, et al. Magnitude of rate of change in kidney function and future risk of cardiovascular events. Int $\mathrm{J}$ Cardiol 2016;202:657-65. 